\title{
ANALYSIS OF DOSE AT 3D-CRT AND IMRT TECHNIQUES IN LEFT BREAST CANCER CASE WITH HYPOFRACTIONATION \\ USING DEEP INSPIRATION BREATH-HOLD (DIBH)
}

\author{
Samsun ${ }^{1)}$, Nursama Heru ${ }^{1)}$ Sriyatun ${ }^{1)}$, Imam Muhamad Fathoni ${ }^{1)}$, Muhammad Arif ${ }^{2)}$, Dwi \\ Cahya Kusuma Putra ${ }^{3)}$, Oky Dharma Riska ${ }^{3)}$, Gregorius Septayudha ${ }^{4)}$, \\ Radiodiagnostic and Radioteraphy. Politeknik Kesehatan Jakarta 2, Jakarta, Indonesia ${ }^{1)}$ \\ Physics Departement, Univercity of Indonesia, Jakarta, Indonesia ${ }^{2)}$ \\ Radioteraphy Deapartment, Rumah Sakit Siloam TB. Simatupang, Jakarta, Indonesia ${ }^{3)}$ \\ Radiology Departement, Rumah Sakit UKI, Jakarta, Indonesia ${ }^{4)}$ \\ Corespondance : Samsun, Radiodiagnostic and Radioteraphy. Politeknik Kesehatan Jakarta 2, Jl. \\ Hang Jebat III Blok F3, Jakarta 12120, Indonesia, Phone / Fax : +62-0217206239 \\ E-mail: aiman_052005@yahoo.com
}

\begin{abstract}
In terms of breast cancer radiation treatment, it has radiation using the 3D-Conformal Radiotherapy (3D-CRT) technique and the continuation of the 3D-CRT technique, namely the Intensity Modulated Radiation Therapy (IMRT) technique. This study aims to evaluate the dosage aspects of PTV and OAR between the 3D-CRT and IMRT techniques in cases of left breast cancer with hypofractionation using the Deep Inspiration Breath Hold (DIBH) method using the Conformity Index (CI) and Homogeneity Index (H.I.) and H.I. organ at risk uses tolerance limits.

This type of research is comparative quantitative with ten samples with primary data conducted at Siloam T.B. Hospital. Simatupang from November 2019 to April 2020. The research was carried out in the form of radiation planning with 3D-CRT techniques and IMRT techniques, and the results of planning both techniques were evaluated between 3D-CRT techniques and IMRT techniques through PTV evaluations using CI and H.I. values. Furthermore, the organs at risk use tolerance limits on each organ.

The results showed the assessment between 3D-CRT and IMRT on PTV and organs at risk received different doses. The PTV shows the CI value, which is almost the same as the difference of 0.034 , and there is a slight difference in H.I. with an average value in the IMRT technique of 0.07 and 3D-CRT of 0.11 , and it can be seen that the IMRT is slightly superior because the excellent H.I. value is the closest to 0 . Then at the dose of organ at risk received by the sample, the 3D-CRT technique is slightly superior by obtaining a lower dose that obtains the difference in the heart by $0.53 \%$, lung by $3.46 \%$, spinal cord by $6.51 \mathrm{~Gy}$, esophagus at $4.5 \mathrm{~Gy}$, and larynx at $5.18 \mathrm{~Gy}$.
\end{abstract}

Keywords: Breast Cancer, 3D-CRT, IMRT, Organ At Risk, CI and H.I.

\section{Introduction}

Breast cancer was initially treated with conventional fractionation, which associated administering a total dose of 45 - 50 Gy (1.8 - 2 Gy per fraction) in 25 - 28 times fractions, but this can now be accomplished with hypofraction. Hypofractionation is administering a total dose of $40.5-42.5$ Gy $(2.66-2.67$ Gy per fraction) in 15-16 times the fraction in breast 
cancer irradiation. Radiotherapy has been shown to accomplish this goal in several experiments conducted abroad. This trial compared hypofractionated Radiotherapy to conventional fractionation as postoperative adjunctive treatment. These findings suggest that the acute and chronic effects of each type of breast cancer irradiation are not significantly different. $(4,5)$

A method known as the Deep Inspiration Breath Hold (DIBH) method delivers a lower dose to the heart and lungs to minimize acute and chronic effects. This method focuses on reducing the dose to the cardiac substructure during radiation treatment for left breast cancer.

While the 3D-CRT technique is the most frequently used for breast cancer radiation treatment, other techniques may be used, one of which is developing the 3D-CRT technique, namely the IMRT technique. 3D Conformal Radiation Therapy (3D-CRT) is a technique for irradiating breast cancer expected to reduce radiation doses delivered to healthy organs. The tumor location can be determined more precisely by using Computed Tomography (C.T.) to simulate and plan radiotherapy treatment. (3). The 3D-CRT technique is widely regarded as the industry standard for treatment planning. However, compared to 3D-CRT, IMRT can provide more excellent target coverage and lower radiation doses to surrounding vital organs.

Among the efforts is using the DIBH method for breast cancer irradiation and cutting-edge radiotherapy technology, specifically the 3D-CRT and IMRT techniques. The goal is similar to Radiotherapy, which delivers the maximum dose possible to the target while sparing the surrounding organs at risk. Additionally, both techniques apply to cases of breast cancer.

The Deep Inspiration Breath Hold (DIBH) method was used to determine the dose of 3DCRT and IMRT techniques in hypofractionated left breast cancer cases.

\section{METHODS OF RESEARCH}

The data collection method used in this study was a discussion with radiotherapists and medical physicists to obtain the necessary information regarding sample selection, analysis of organs at risk to be studied, and processing of CI and H.I. data. Then, using experimental experiments at TPS, we obtained 3D-CRT and IMRT techniques in one patient who met the research inclusion criteria, with a sample size often, and we observed and recorded data from the results of TPS calculation planning, specifically DVH 3D-CRT and IMRT techniques in cases of left breast cancer treated with hypofractionation using the DIBH method. Following data processing in this study, the results of TPS planning for each patient will be compared 
using the DVH diagram. The dose value on the PTV and organ at risk is determined using DVH. At PTV, the data will be processed using CI and H.I. and then compared to the tolerance limit for the organ at risk. After evaluating and comparing the dose values for PTV and organ at risk for each patient using 3D-CRT and IMRT techniques, conclusions will be drawn regarding which technique is the most optimal for $\mathrm{CI}$ and H.I. values and organ at risk in cancer patients. Hypofractionation of the left breast using the DIBH method.

\section{RESULTS AND DISCUSSION}

The results obtained in the form of DVH result from treatment planning performed by Medical Physicists in the TPS room. DVH indicates the dose and volume values for PTV and organs at risk, which correspond to the dose tolerance limit, and the quality of the dose distribution in the target being evaluated by examining the CI and H.I. parameters.

The radiation planning results were evaluated for their suitability for the target shape, homogeneity of the target volume, and dose to at-risk organs nearby the target. The CI and H.I. values were used to determine the dose distribution's suitability for the target tumor or PTV. The conformity index is defined in ICRU report 83 as the degree to which the prescribed dose covers the tumor target and is expressed in equation 1.

$$
C I=\frac{\text { Treated Volume }}{\text { PTV }} \text { (Persamaan 1) }
$$

Where PTV Volume is 95 percent of Treated Volume and Treated Volume is PTV Volume The ideal conformity index value is 1 , which indicates that the isodose curve for the prescribed dose fits the PTV perfectly.

The homogeneity index, defined in equation 2 , is a ratio between the maximum and minimum doses in the target volume; a lower value indicates a more homogeneous dose distribution.

$$
H I=\frac{D 2 \%-D 98 \%}{D 50 \%}(\text { Persamaan 2) }
$$

Where D2\% is the dose that covers $2 \%$ of the PTV volume, D98\% is the dose that covers $98.9 \%$ of the PTV volume, and D50\% is the dose that covers $50 \%$ of the PTV volume. The outstanding homogeneity index value is 0 , which indicates that all doses on PTV are homogeneous.

DIBH, CI, and H.I. values were determined based on the results of a study on ten samples of hypofractionated left breast cancer patients. 


\begin{tabular}{|c|c|c|c|c|c|c|c|c|c|c|}
\hline \multirow{2}{*}{\multicolumn{5}{|c|}{$\begin{array}{l}\text { Tabel 1. Nilai Conformity Index 3D-CRT dan } \\
\text { IMRT }\end{array}$}} & \multicolumn{6}{|c|}{ Tabel 2. Nilai Homogeinity Index 3D-CRT dan IMRT } \\
\hline & & & & & \multirow[t]{2}{*}{ Sampel } & \multirow[t]{2}{*}{ Teknik } & \multirow[t]{2}{*}{ D2\%(Gy) } & \multirow{2}{*}{$\begin{array}{l}\text { D50\% } \\
\text { (Gy) }\end{array}$} & \multirow{2}{*}{$\begin{array}{l}\text { D98\% } \\
\text { (Gy) }\end{array}$} & \multirow[t]{2}{*}{ H.I. } \\
\hline \multirow[t]{2}{*}{ Sampel } & \multirow[t]{2}{*}{ Teknik } & \multirow{2}{*}{$\begin{array}{l}\text { TV } \\
\text { (cm3) }\end{array}$} & \multirow{2}{*}{$\begin{array}{l}\text { PTV } \\
(\mathrm{cm} 3)\end{array}$} & \multirow[t]{2}{*}{$\mathrm{Cl}$} & & & & & & \\
\hline & & & & & \multirow[t]{2}{*}{ A } & 3D-CRT & 44,93 & 43,63 & 40,44 & 0,10 \\
\hline \multirow[t]{2}{*}{ A } & 3D-CRT & 1045,2 & 1065,3 & 0,981 & & IMRT & 44,95 & 43,78 & 42,08 & 0,06 \\
\hline & IMRT & 1063,5 & 1065,3 & 0,998 & \multirow[t]{2}{*}{ B } & 3D-CRT & 45,09 & 43,85 & 40,99 & 0.09 \\
\hline \multirow[t]{2}{*}{ B } & 3D-CRT & 635,7 & 642,9 & 0,988 & & IMRT & 45,34 & 43,72 & 42,01 & 0.07 \\
\hline & IMRT & 641,3 & 642,9 & 0,997 & \multirow[t]{2}{*}{ C } & 3D-CRT & 45,03 & 43,49 & 41,15 & 0,08 \\
\hline \multirow[t]{2}{*}{ C } & 3D-CRT & 441,2 & 443,5 & 0,994 & & IMRT & 45,57 & 43,96 & 42,16 & 0,07 \\
\hline & IMRT & 443,3 & 443,5 & 0,999 & \multirow[t]{2}{*}{ D } & 3D-CRT & 46,05 & 43,96 & 41,89 & 0,09 \\
\hline \multirow[t]{2}{*}{ D } & 3D-CRT & 546,2 & 548,6 & 0,995 & & IMRT & 44,94 & 43,36 & 41,04 & 0,08 \\
\hline & IMRT & 547,5 & 548,6 & 0,997 & \multirow[t]{2}{*}{$\mathbf{E}$} & 3D-CRT & 45,20 & 44,26 & 38,96 & 0,14 \\
\hline \multirow[t]{2}{*}{$\mathbf{E}$} & 3D-CRT & 304,5 & 317,5 & 0,959 & & IMRT & 44,66 & 43,53 & 42,03 & 0,06 \\
\hline & IMRT & 317,2 & 317,5 & 0,999 & \multirow[t]{2}{*}{$\mathbf{F}$} & 3D-CRT & 44,70 & 42,78 & 38,86 & 0,13 \\
\hline \multirow[t]{2}{*}{$\mathbf{F}$} & 3D-CRT & 734,6 & 847,4 & 0,866 & & IMRT & 44,83 & 43,60 & 42,08 & 0,06 \\
\hline & IMRT & 846,6 & 847,4 & 0,999 & \multirow[t]{2}{*}{ G } & 3D-CRT & 45,05 & 43,54 & 40,16 & 0,11 \\
\hline \multirow[t]{4}{*}{ G } & 3D-CRT & 511,8 & 524,2 & 0,976 & & IMRT & 44,75 & 43,44 & 42,19 & 0,05 \\
\hline & & & & & \multirow[t]{3}{*}{ H } & 3D-CRT & 45,21 & 43,92 & 39,38 & 0,13 \\
\hline & IMRT & 524,1 & 524,2 & 0,999 & & & & & & \\
\hline & 3D-CRT & 4649 & 4821 & 0964 & & IMRT & 45,25 & 43,92 & 42,09 & 0,07 \\
\hline \multirow{2}{*}{ H } & SD-CA & 404,J & 402,1 & 0,504 & \multirow[t]{2}{*}{ I } & 3D-CRT & 44,91 & 43,56 & 38,87 & 0,13 \\
\hline & IMRT & 481,2 & 482,1 & 0,998 & & IMRT & 45,69 & 44.10 & 41,89 & 0,08 \\
\hline I & 3D-CRT & 417,1 & 437,1 & 0,954 & & & & & & \\
\hline & & & & & J & 3D-CRT & 44,87 & 43,29 & 39,85 & 0,11 \\
\hline & IMRT & 435,9 & 437,1 & 0,997 & & IMRT & 45,06 & 43,64 & 42,05 & 0,06 \\
\hline J & 3D-CRT & 303,5 & 313,3 & 0,968 & & & & & & \\
\hline & IMRT & 312,9 & 313,3 & 0,998 & & & & & & \\
\hline
\end{tabular}

The results of the calculation of the CI value obtained from equation 1 for PTV in the 3DCRT technique and IMRT in the case of left breast cancer treated with hypofractionation using the DIBH method are presented in Table 1. The calculation of ten samples using the 3D-CRT technique yields a confidence interval (CI) of 0.866 to 0.995 , while the IMRT 
technique yields a CI of 0.997 to 0.999 . Overall, the average CI value for each sample was 0.964 for the 3D-CRT technique and 0.998 for the IMRT technique.

When the average CI value for the IMRT technique is 0.998 , it demonstrates that the 3DCRT and IMRT techniques for CI at PTV 10 samples studied in cases of left breast cancer treated with hypofractionation using the DIBH method are nearly identical with a difference of only 0.034 , because the ideal value for $\mathrm{CI}$ is 1 , which indicates that the isodose curve for the prescribed dose of PTV coincides.

In Table 2, the H.I. calculation results for ten samples using the 3D-CRT technique range from 0.08 to 0.14 , while the IMRT technique ranges from 0.08 to 0.05 . Overall, the average H.I. value for each sample was 0.11 using the 3D-CRT technique and 0.07 when using the IMRT technique.

When the average value of H.I. in the IMRT technique is 0.07 , it demonstrates that the IMRT technique is superior to the 3D technique for PTV 10 samples studied in cases of left breast cancer treated with hypofractionation using the Deep Inspiration Breath Hold (DIBH) method. -CRT with a difference of 0.04 , and the results of this study are consistent with the provisions of ICRU report 83, as described in the previous Theory Study, that the ideal value for the homogeneity index is 0 , indicating that all doses in the PTV are homogeneous. Additionally, the IMRT technique achieves an H.I. value that is closer to zero than the 3DCRT technique.

The IMRT technique's homogeneity is due to optimization in the treatment planning process, which ensures that the dose received by the PTV is the same in each direction of the beam. Based on the study results, different tolerance limits for each organ, namely the heart, lung, spinal cord, esophagus, and larynx, will be used in cases of left breast cancer treated with hypofractionation using the DIBH method, as illustrated in Fig. Table 3.

Tabel 3. Batasan toleransi pada Kanker Payudara (9-11)

\begin{tabular}{ccc}
\hline $\begin{array}{c}\text { Organ At } \\
\text { Risk }\end{array}$ & $\begin{array}{c}\text { Teknik } \\
\text { Penyinaran }\end{array}$ & $\begin{array}{c}\text { Nilai } \\
\text { Rata- } \\
\text { Rata }\end{array}$ \\
\hline $\begin{array}{c}\text { LUNG V20 } \\
\mathbf{3 7} \%\end{array}$ & $3 \mathrm{D}$ & $\mathbf{2 4 , 6 1 \%}$ \\
\cline { 2 - 3 } & IMRT & $\mathbf{2 8 , 0 7 \%}$ \\
\hline $\begin{array}{c}\text { HEART V25 } \\
\leq \mathbf{1 0 \%}\end{array}$ & $3 \mathrm{D}$ & $0,82 \%$ \\
\cline { 2 - 3 } & IMRT & $1,35 \%$ \\
\end{tabular}

Tabel 4. Nilai Dosis pada OAR dengan Batasan Toleransi antara teknik 3D-CRT dan IMRT

\begin{tabular}{ccccc}
\hline Structure & Volume & Dose & $\begin{array}{c}\text { Mean } \\
\text { Dose }\end{array}$ & $\begin{array}{c}\text { Max } \\
\text { Dose }\end{array}$ \\
\hline Heart & $10 \%$ & $\leq$ & - & - \\
& & $25 \mathrm{~Gy}$ & & \\
\hline Lung & $37 \%$ & $\leq$ & - & - \\
& & $20 \mathrm{~Gy}$ & & \\
\hline Esophagus & - & - & $\leq$ & - \\
& & & $34 \mathrm{~Gy}$ &
\end{tabular}




\begin{tabular}{|c|c|c|c|c|c|c|c|}
\hline \multirow{3}{*}{$\begin{array}{c}\text { SPINAL } \\
\text { CORD Dmax } \\
=37(\mathrm{~Gy})\end{array}$} & $3 D$ & $4,78 \mathrm{~Gy}$ & \multirow[t]{2}{*}{ Larynx } & \multirow[t]{2}{*}{-} & \multirow[t]{2}{*}{-} & \multirow{2}{*}{$\begin{array}{c}\leq \\
45 G y\end{array}$} & \multirow[t]{2}{*}{-} \\
\hline & \multirow{2}{*}{ IMRT } & \multirow{2}{*}{$11,1 \mathrm{~Gy}$} & & & & & \\
\hline & & & Spinal & - & - & - & $\leq 45$ \\
\hline \multirow{2}{*}{$\begin{array}{c}\text { ESOPHAGUS } \\
\text { Dmean } \leq \\
34(\mathrm{~Gy})\end{array}$} & $3 D$ & $4,13 \mathrm{~Gy}$ & Cord & & & & Gy \\
\hline & IMRT & $8,63 \mathrm{~Gy}$ & & & & & \\
\hline \multirow{2}{*}{$\begin{array}{c}\text { LARYNX } \\
\text { Dmean } \leq \\
\text { 45(Gy) }\end{array}$} & $3 D$ & $2,34 \mathrm{~Gy}$ & & & & & \\
\hline & IMRT & 7,52 Gy & & & & & \\
\hline
\end{tabular}

The dose tolerance limits for each organ, namely the heart, lung, esophagus, larynx, and spinal cord, are listed in Table 3. The tolerance limit V25 10\% indicates that the percentage of dose distribution obtained at $25 \mathrm{~Gy}$ by the heart should not exceed $10 \%$ of the heart volume and V20 37\% for the lung. The tolerance limit of Dmean 34 Gy explains that the average dose received by the esophagus should not exceed $34 \mathrm{~Gy}$, while the larynx and spinal cord should receive Dmean 45 Gy and Dmax 45 Gy, respectively.

The results of the ten samples analyzed revealed variations in the organs at risk (heart, lung, spinal cord, esophagus, and larynx). In this organ, it is observed that the 3D-CRT technique delivers lower doses to all organs at risk than the IMRT technique. The dose differences between these two methods were $0.53 \mathrm{~Gy}, 3.46 \mathrm{~Gy}, 6.51 \mathrm{~Gy}, 4.5 \mathrm{~Gy}$, and $5.18 \mathrm{~Gy}$ for the heart, lungs, spinal cord, esophagus, and larynx, respectively. The dose received by the organ at risk is still below the dose tolerance limit.

\section{CONCLUSION}

According to the study's findings, there were differences in the Conformity Index (CI) and Homogeneity Index (H.I.) values between the 3D-CRT and IMRT techniques for the ten samples studied. The average Conformity Index (CI) for the IMRT technique was 0.998, while the 3D-CRT technique had a value of 0.964 , indicating that the values are nearly identical between the two techniques. And the IMRT technique's average Homogeneity Index (H.I.) value is 0.07 , while the $3 \mathrm{D}-\mathrm{CRT}$ technique's value is 0.11 , indicating that the IMRT technique is closer to the ideal value of 0 .

And the results of the study on ten samples examined indicated that all organs at risk, namely the heart, lung, spinal cord, esophagus, and larynx, received a lower dose in the 3D-CRT technique than in the IMRT technique, with a difference of 0.53 percent for the heart, 3.46 
percent for the lung, 6.51 Gy for the spinal cord, 4.5 Gy for the esophagus, and 5.18 Gy for the larynx. Additionally, the entire organ is within the tolerance dose limit.

\section{REFERENCES}

1. Bray F, Ferlay J, Soerjomataram I. Global Cancer Statistics 2018: GLOBOCAN Estimates of Incidence and Mortality Worldwide for 36 Cancers in 185 Countries. Am Cancer Soc. 2018;412-24.

2. Indonesian, Radiation Oncology. Kesintasan Hidup Dan Kekambuhan Lokoregional Berdasarkan Prosedur Pengobatan Pada Penatalaksanaan Kanker Payudara Stadium Lanjut Lokal. Radioter Onkol Indones. 2012;3(3):73-109.

3. Ayfer Haydaroglu, M.D. Gokhan Ozygit MD. Principles and Practice of Modern Radiotherapy Techniques in Breast Cancer [Internet]. 1st ed. Ayfer Haydaroglu, M.D. Gokhan Ozygit MD, editor. Vol. 1, Springer Science+Business Media New York. Izmir, Turkey: Senem Demirci Alanyalı, Naim Ceylan, and Ayfer Haydaroglu; 2013. 117, 183-358 p. Available from: www.springer.com

4. Mohsin Khan, Manoj K Gupta RKS. Hypofractionated Radiotherapy Induced Pulmonary Function Changes and Toxicity Analysis in Breast Cancer Patients Post-mastectomy Chest Wall. J Med Sci Clin Res [Internet]. 2014;2(5):1039-48. Available from: www.jmscr.igmpublication.org

5. Rachel C. Blitzblau, Sua Yoo and JKH. Radiation Therapy Techniques and Treatment Planning for Breast Cancer [Internet]. Series Edi. Nancy Y. Lee and JJL, editor. Springer International Publishing Switzerland. Boston, USA; 2016. 12-158 p. Available from: http://www.springer.com/series/13580

6. Oechsner M, Düsberg M, Borm KJ, Combs SE, Wilkens JJ, Duma MN. Deep inspiration breathhold for left-sided breast irradiation: Analysis of dose-mass histograms and the impact of lung expansion. Radiat Oncol [Internet]. 2019;14(1):1-10. Available from: biomedcentral.com/submissions

7. Ph D, Lyden ER, Brown CK, Morano K. Author Manuscript. 2013;82(5):1764-70.

8. Balagamwala EH, Stockham A, Macklis R, Singh AD. Introduction to radiotherapy and standard teletherapy techniques. Dev Ophthalmol. 2013;52:1-14.

9. Lilenbaum R, Komaki R, Martel MK. Radiation Therapy Oncology Group Rtog 0623 a Phase li Trial of Combined Modality Therapy With Growth Factor. Cycle. 2008.

10. Charles M. Washington DL. Principles and Practice of Radiation Therapy [Internet]. 4th ed. Passmore GC, editor. St. Louis, Missouri, United States: Elsevier Ltd; 2016. 82-908 p. Available from: http://evolve.elsevier.com

11. Hoskin P. Radiotherapy in Practice: External Beam Therapy. 3th Editio. Hoskin P, editor. Vol. 3th Editio, Oxford University Press. United Kingdom: Oxford University Press; 2019 
